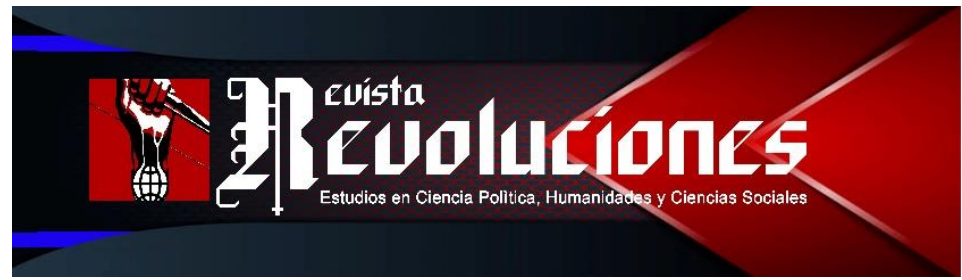

\title{
MARIANO ISIDRO DE LA BARRERA, ESCRIBIENTE Y COMPAÑERO DE TUPAC AMARU: LA REBELIÓN ANDINA A LA LUZ DE NUEVOS DOCUMENTOS HISTÓRICOS
}

\author{
Mariano Isidro de la Barrera, scribe and companion of Tupac Amaru: the \\ Andean rebellion in the light of new historical documents
}

\author{
Luis Miguel Glave ${ }^{1}$ \\ UNIVERSIDAD PABLO DE OLAVIDE, SEVILLA \\ ESPAÑA \\ lmglave@hotmail.com \\ https://orcid.org/o000-0003-1452-7017
}

DOI: https://doi.org/10.35622/j.rr.2021.05.002

Recibido: 01-VI-2021 / Aceptado: 16-VII-2021 / Actualizado: 21-VII-2021

\section{Resumen}

\begin{abstract}
Este artículo traza una semblanza sobre un personaje estrechamente ligado a José Gabriel Condorcanqui Tupac Amaru II. Pretende abrir nuevas perspectivas al conocimiento de la gran rebelión de los Andes de 1780-1782, desde una visión más cercana a las actitudes y vicisitudes de la vida de los principales actores de la conmoción popular. Se centra en la figura de Mariano de la Barrera y también de Miguel Montiel, confidentes cercanos a Tupac Amaru en los años previos al inicio de la rebelión. Termina rescatando el trágico capítulo del destierro que sufrió de la Barrera y otros luego de derrotado el movimiento.
\end{abstract}

Palabras Clave: Rebeliones andinas, Tupac Amaru, conspiraciones, ideología política, destierro.

\begin{abstract}
This article outlines a sketch on a character closely linked to José Gabriel Condorcanqui Tupac Amaru II. It aims to open new perspectives to the knowledge of the great rebellion of the Andes of 1780-1782, from a vision closer to the attitudes and vicissitudes of the life of the main actors of the popular commotion. It focuses on the figure of Mariano de la Barrera and also of Miguel Montiel, confidants close to Tupac Amaru in the years before the beginning of the rebellion. He ends up rescuing the tragic chapter of the exile he suffered from the Barrier and others after the movement was defeated.
\end{abstract}

\footnotetext{
${ }^{1}$ Fundador del Centro Bartolomé de las Casas del Cusco, y luego investigador del Instituto de Estudios Peruanos. Actualmente es investigador afiliado al Colegio de América de la Universidad Pablo de Olavide de España e investiga en el Archivo General de Indias de dicha ciudad. Entre sus principales publicaciones están $L a$ república instalada: Formación nacional y prensa en el Cusco, 1825-1839 (2004); De Rosa y espinas: Economía, sociedad y mentalidades andinas, Siglo XVII (1998); Vida, símbolos y batallas: Creación y recreación de la comunidad indígena, Cusco, siglos XVI-XX (1992); Trajinantes: caminos indígenas en la sociedad colonial, siglos XVI-XVII (1989).
} 
Keyword: Andean rebellions, Tupac Amaru, conspiracies, political ideology, banishment.

\section{INTRODUCCIÓN}

El personaje al que está dedicado este estudio ya es conocido en la amplia literatura tupamarista. No es necesario detenernos en referir las siempre breves menciones, dejadas casi al paso, que sobre él aparecen en los muchos estudios dedicados al rebelde de Tinta, sólo haremos un breve resumen, que en realidad es todo lo que aparece en esos estudios y que se repite una y otra vez como un viejo disco de vinilo rallado. Mariano Isidro de la Barrera dejó algunas huellas que aparecen en la documentación de las colecciones publicadas acerca de la rebelión. En la Colección de documentos que se publicaron con motivo del bicentenario de la rebelión, figuran en los expedientes referencias a Mariano de la Barrera como "apoderado" de Tupac Amaru en Lima. Se sabe por ellas que era quien le veía el caso de su juicio por la legítima descendencia del inca y la herencia del marquesado de Oropesa y, cuando ya estaba declarada la rebelión, José Gabriel le escribió una famosa esquela en la que le dice que ya ejecutó al corregidor Arriaga y lo apremia para que se vaya al Cuzco, y que lo haga, "aunque sea a pie y por caminos extraviados"2. En los autos del juicio del cacique rebelde sale también que fue Barrera un confidente cercano de sus ideas de rebelión y con él confirió, según un patético último testimonio de confesión del reo, en el cerro de Piccho, que se podía juntar a todos los corregidores y que esto era posible para proceder contra ellos. Tupac Amaru dijo siempre que lo tenía como a uno de su casa, y veremos al final cuán cierto era.

Digamos también que, junto a Barrera, el otro amigo y pariente del rebelde, implicado igualmente en Lima era Miguel Montiel. Como sabemos, Tupac Amaru estuvo en Lima entre abril y fin del año 1777 siguiendo su juicio sobre la legítima descendencia del inca. Fue durante esos meses que se reunió con estos allegados y amigos y de allí provino la sospecha que se cernió sobre ellos. Montiel era otro personaje que apareció en la historia previa a la rebelión y que ha sido recogido, someramente, en el corpus al uso de la literatura tupamarista, siempre al mismo estilo de repetir hasta el hartazgo una misma evidencia 3 .

Sobre ambos amigos de Tupac Amaru, existe un pequeño texto que se usa para documentar su presencia en el escenario de la rebelión4. El secretario Gómez Enríquez, obedeciendo una orden del virrey, que estaba siguiendo las indicaciones que recibió en 10 de noviembre de 1784, para que se averiguase si había constancia de haberse hecho procesos a sujetos contra quienes había indicios de tener conocimiento o complicidad con Tupac Amaru, informa lo que se ejecutó en el caso de Barrera. El virrey Jáuregui mandó se hiciesen averiguaciones cuando el fuego de la rebelión había prendido en algunas provincias. De estas resultó la prisión de Barrera y Montiel. El oidor Manuel de Arredondo practicó la sustanciación de las

\footnotetext{
${ }^{2}$ Luis Durand F. (ed), Colección documental del bicentenario de la revolución emancipadora de Tupac Amaru. Lima, 1980.

3 Llamó acertadamente la atención sobre el personaje Edgar Montiel, "Las "ediciones" en los Comentarios reales y sus lecturas en el siglo de la Independencia”. Solar 5 (2009) 39-56. Se basó en los hallazgos de Carlos Daniel Valcárcel, quien revisó el expediente que comentaremos en seguida.

4 Archivo General de Indias (AGI), Cuzco 32. Reproducido en Colección documental.... Tomo V, 629.
} 
causas y de ello resultó que no hubo evidencias contra ellos, por lo que fueron amonestados pero puestos en libertad. Ya libres, resultó que el visitador Areche remitió unas famosas esquelas que Tupac Amaru escribiera a ambos y que fueron interceptadas por unos curas que las derivaron al obispo. Con esa evidencia, Arredondo volvió a apresarlos y abrirles causa. Hecha la acusación fiscal y recibida la causa a prueba, en el término de ella se publicó el indulto general con el que la corona pretendió apaciguar los ánimos de la rebelión luego de la ejecución del líder. Pidieron ser comprendidos en ello. La Sala del Crimen convino en ello con condición de que no salieran de la capital. Barrera la quebrantó y con el nombre fingido de Antonio Cordero fue aprehendido en la provincia de Tarma donde estaba involucrado en un intento de alzamiento que encabezó el cacique de Cayna Manuel perfecto Llacsa5. Reagravó su delito por las sospechosas conversaciones que tuvo en Lima con Mariano Condorcanqui y Andrés Mendigure y, por el mérito de su causa, le sentenció la Sala a destierro perpetuo y prisión de ocho años en Africa.

El caso de Cordero se encuentra reunido en un grueso legajo del Archivo General de Indias. Titulado como "Sublevaciones del Perú: Túpac Amaru" trae como descriptores "Correspondencia y expedientes sobre sublevaciones en el Perú: Fernando Tupac Amaru, provisión de cacicazgos, complicidad de curas, Mariano Barrera (1782-1788)”. Eso dice el título del legajo, pero en realidad se trata de una causa seguida contra nuestro interesante sospechoso. Son tres cuadernos de los Autos seguidos contra Mariano Isidro de la Barreda(sic) por confidente del rebelde José Gabriel Condorcanqui conocido por Tupa Amaro. Año de 1780. Real Sala del Crimen. Escribano de Cámara Don Clemente Castellanos. Y un cuaderno de la segunda causa promovida contra el mismo Barrera, de 1783, que como ya mencionamos, lo llevó al destierro en Africa. En el primero de los cuadernos de la causa que se siguió a fines de 1780, el proceso de Barrera va unido al del otro detenido por sospechas de vinculación con la rebelión, Miguel Montiel y Surco $^{6}$.

El expediente viene adjunto a una carta del virrey Caballero de Croix de 31 de marzo de 1786, que le escribe al Marqués de Sonora dando cuenta del envío de esta causa y resumiendo el caso de este reo. A inicios de la rebelión, como ya indicamos, se investigó las posibles vinculaciones limeñas de Tupac Amaru y se detuvo a Barrera. Se aseguraba que Tupac Amaru mantenía correspondencia con algunos sujetos y se comisionó a los oidores Manuel Mansilla, Marqués de Corpa y Manuel de Arredondo para que practicasen las diligencias convenientes. Se le detuvo y se le dejó libre ya que acreditó ser inocente de la infidencia. Pero Areche encontró unas cartas donde se confirmaba que Barrera (que es el apellido más repetido frente a Barreda) sabía de las intenciones de Tupac Amaru, por lo que se le detuvo nuevamente. Vino el indulto al que se acogió el reo y lo libertaron con condición de que no dejara la ciudad, lo que no cumplió, saliendo a Tarma haciéndose llamar Antonio Cordero, por lo que fue aprehendido allí por su genio "perturbativo". Remitido a Lima, mantuvo varios encuentros con Mariano Condorcanqui y Andrés Mendigure, por lo que, como señalamos, fue sentenciado a destierro perpetuo y cárcel de ocho años en Africa. Lo embarcaron con otros

5 AGI, Cuzco 29; AGI, Lima 668, $\mathrm{N}^{\circ} 56$

${ }^{6}$ AGI, Lima 1049

Revista Revoluciones -7- Vol. 3, Nº 5 (2021), pp. 5-19

Esta obra está bajo una licencia internacional Creative Commons Atribución 4.0. 
reos de su clase. La carta del virrey repite el informe que le había hecho el secretario Enríquez que le sirve para presentar los autos que se remitieron al Consejo de Indias.

\section{El proceso a Miguel Montiel y Mariano Barrera (1780)}

El Marqués de Corpa fue comisionado por el virrey para apresar a dos sospechosos de estar vinculados con el rebelde Tupac Amaru. Detuvo a Miguel Montiel Surco y José Vicente García y procedió a tomarles sus declaraciones. El oidor ofició al virrey para participarle sus averiguaciones e informarle así mismo que no procedió igual con Juan de los Santos y Maldonado Poma Ynga. Más adelante, en otro proceso, declaró este sospechoso ser hijo de N. de los Santos Poma Ynga natural de Anta y de Rosa Maldonado de Cuzco, era sastre y dijo haber salido muy niño de Cuzco y no saber ni siquiera si su madre todavía vivía. Santos debió ser apresado por la misma orden, pero por haber sido necesario carearlo con el "coronel de indios" que igualmente de orden del virrey puso preso otro comisionado, Manuel Mansilla, quedó a cargo suyo. El referido coronel de indios no era otro que Laureano de los Reyes de cuya historia ya hemos escrito7.

Como señalamos, Miguel Montiel tiene un lugar estelar en la literatura tupamarista en virtud de su relación con el rebelde, que, según estos testimonios, fue bastante estrecha e incluyó un préstamo monetario bastante elevado. A partir de su detención por sospechoso de estar relacionado con José Gabriel, sabemos de las reuniones que se llevaban a cabo entre varios contertulios donde se leía al Inca Garcilaso y se hablaba de la licitud de la conquista y los derechos de los nobles indios. Este documento es el único registro encontrado hasta ahora de este bastante misterioso y sugerente actor de los sucesos vinculados a la rebelión andina.

Aunque las menciones a Montiel y, en menor medida a Barrera, siempre se basan en este expediente, nunca se ha hecho una revisión del mismo en detalle. Era necesario hacerlo, para conocer quién o quiénes dieron testimonios acusatorios, qué adujeron los sospechosos, cuál fue el tenor de los testimonios, qué ideas generales acerca de la política y la historia destilan, cuál era la ubicación social de los declarantes, en fin, hacer un adecuado análisis interno del documento. El método de exposición de esta parte del estudio será seguir de la manera más precisa los actuados del proceso, desarrollando de manera intercalada, observaciones que nos permitan construir una visión general que nos acerque al escenario de reuniones y relaciones que se dieron en los años previos al estallido de la gran rebelión andina de $1780^{8}$.

/1v/ Las declaraciones que se le tomaron a Montiel son las siguientes. Miguel Montiel y Surco, natural de Oropesa en Quispicanchis, había viajado por Europa y era mercader con tratos con Tupac Amaru a quien conoció hacía tres años cuando pasó por Lima a seguir un pleito con José García “sobre la descendencia del último Inga”. José Gabriel asistía en la habitación del

7 Luis Miguel Glave, "El archivo indígena y el relato de su historia en los Andes”. Naveg@mérica. Revista electrónica Editada Por La Asociación Española De Americanistas $25 \quad$ (2020) https://doi.org/10.6018/nav.441421

8 AGI, Lima 1049. Testimonio del Cuaderno $1^{\circ}$ de los Autos seguidos contra Mariano Isidro de la Barreda por confidente del rebelde José Gabriel Condorcanqui conocido por Tupa Amaro, año de 1780. Real Sala del crimen, escribano de cámara, don Clemente Castellanos. 
maestro Julián Moreno, de oficio sastre, donde también iba Montiel y allí trabaron amistad. /6v/ Según sus declaraciones, a los quince años Montiel "salió" a Potosí, suponemos que desde su natal Cuzco, se afincó luego en Lima y de allí viajó con don Guillermo Ros y Monroy a España y luego a Londres, donde permaneció cinco años y posteriormente viajó a Francia. Fue en 1769 a Cádiz y volvió al Perú en 1770 en el navío Marchante el Astuto de don Marcelino Martínez Junquera, con quien Montiel mantuvo tratos comerciales. Contaba 44 años el 7 de diciembre de 1780 cuando hace estas declaraciones al haber sido tomado prisionero para hacer las averiguaciones acerca de las posibles correspondencias del levantamiento. Esta es la sucinta biografía que el mismo Montiel nos ha dejado y que circula en la literatura sobre la rebelión.

/7v/ Como vimos, junto a Montiel, el oidor comisionado detuvo también a otro sospechoso. Se trató de José Vicente García, el yerno del rival de José Gabriel a la legítima descendencia del inca de Vilcabamba. Fue García el verdadero contendiente judicial del cacique de Tinta. Por sus relaciones con la nobleza nativa, su activismo judicial y político en Lima, a pesar de ser un enemigo de José Gabriel, el virrey lo tenía en la lista de sospechosos. En sus declaraciones, García dijo que sólo tenía relación con el rebelde porque tenía el famoso pleito por la descendencia del inca y el derecho al marquesado de Oropesa. García, como acabamos de decir, era el artífice de las gestiones que su suegro Diego de Betancur Tupac Amaru llevaba adelante por esa descendencia. Era el que había recopilado documentos, buscado procuradores, estudiado las alegaciones, posiblemente más por su propia iniciativa que de la del suegro9. El declarante señaló que por eso tenía enemistad con el rebelde y no supo de su levantamiento sino cuando ejecutó al corregidor, como se lo comunicó por una esquela el notario cuzqueño Bernardo José Gamarra. Tenía 32 años.

/10/ El expediente nos descubre un hecho paradójico. En la certificación del notario Castellanos, que llevaba los actuados, sobre los papeles de García que se hallaron en un cajoncito de la tienda de mercaderías en la Calle de los Judíos, dice que allí también vivía Miguel Montiel. Sólo eran algunos papeles atrasados referidos a la dependencia que contrajo con él por un dinero. Montiel pues tenía también un vínculo con el rival de José Gabriel.

Ya luego, los autos siguieron el 20 de diciembre de 1780, cuando hicieron comparecer a un español, montañés, recientemente arribado a la ciudad de Los Reyes y que tendría particular protagonismo en las acusaciones contra Montiel. Se llamaba Francisco Fernández Olea y se le hizo declarar lo que sabía sobre Tupac Amaru y si había oído que tuviera en esta capital alguna correspondencia o amistad. Dijo que "tiene entendido" que Montiel seguía correspondencia con Tupac Amaru. Llama cajonero en la calle de los judíos a Montiel a quien

\footnotetext{
9 Entre tantos importantes documentos que Francisco Loayza dio a la imprenta, figura un resumen del pleito que elaboró el propio Tupac Amaru. Fue la primera vez que se difundió este tema. Francisco Loayza, Genealogía de Tupac Amaru. Por José Gabriel Tupac Amaru (Documento inédito del año 1777). Lima, Pequeños grandes libros de la historia americana, 1946. Cabe señalar que la signatura del AGI de donde Loayza afirma haber tomado el documento, es errónea. El más destacado estudio en profundidad del pleito entre Betancur y José Gabriel es el de David Cahill, "Primus inter pares. La búsqueda del marquesado de Oropesa camino a la gran rebelión (1741-1780)”. Revista Andina 37 (2003) 9-35.
} 
le oyó decir que tenía conocimiento y tratos con el rebelde y que le había fiado cantidad de pesos. Así mismo le oyó "que los caciques tienen privilegios de grandes de España y que, por serlo José Gabriel Tupac Amaru y pariente más inmediato de los emperadores Ingas, se le vería brevemente andar en silla de manos" /12/. Cuando se lo replicó al cajonero, este se enardeció y se ratificó en lo expresado "añadiendo que serían expelidos de este reino los españoles por estar mal ganado por el rey de España y ser legítimo el referido Tupac Amaru como quinto nieto de los Ingas". Todavía le requirió Olea a Montiel por quiénes serían los que expelieran a los españoles, le replicó que si no bastaban los indios se auxiliarían de los ingleses que tienen un mejor gobierno. Olea tuvo impulsos de "tomar satisfacción" al escuchar esto, pero se contuvo por estar en casa de Montiel. No dio parte incontinenti a la justicia "por ser nuevo en esta ciudad y no persuadirse que lo dijese con intención, hasta que ha sido sabedor del alzamiento de la provincia de Tinta”. La conversación, tuvo lugar seis u ocho días antes de saberse en Lima la noticia del alzamiento. Olea además afirmó que dos sujetos que entendió eran naturales del Cuzco visitaban a Montiel y fue con uno de aquellos que se manifestó la conversación que refirió y trató sobre la conquista del reino, "de que estaban instruidos, especialmente Montiel quien frecuentemente estaba leyendo la Historia de este reino en un autor que él nombraba los Comentarios de los Ingas" /13v/. Montiel habría abonado sus asertos en cuanto a los privilegios de los caciques con la especie, que Olea menospreció, de que el Conde del Puerto había solicitado saber si Tupac Amaru tenía alguna hija para casarla con su hijo.

No hay en los autos ninguna otra declaración incriminatoria acerca de estas conversaciones, salvo una extemporánea, que expondremos más adelante, que se añadió, tal vez justamente por lo endeble de sustentar una acusación en base a un testimonio. Así, fue Olea, un gallego recién arribado a la ciudad de Los Reyes, nuestro único testigo sobre esta preciosa pieza de comunicación oral de un pensamiento muy extendido entre los nobles indios del Perú. A la vez que quiso denunciar una conducta sospechosa de infidencia por parte del comerciante Montiel, Olea involuntariamente dejó a los historiadores una pista del más alto interés acerca de estas lecturas de Garcilaso y de esta expresión política indigenista.

/14v/ El 22 de diciembre fue el oidor Manuel de Arredondo quien pasó a la guardia de infantería donde mantenían a Montiel y lo hizo comparecer ante sí. Le preguntó por sus amistades y quiénes lo visitaban en su casa o cajón. Dijo no tener amistad estrecha con nadie en esta ciudad y de los conocidos que más frecuentaban su cajón estaba don Antonio Pimentel, pasante de abogado, natural del Cuzco, hijo del corregidor que fue de Urubamba y que vive en la casa del Conde de Torre Velarde; el hijo de este llamado don Agustín, aunque muy de tarde en tarde; José Bostense, Francisco Beira y Melchor de Ibarra. Para escribir sus cartas se valía de Pimentel, Bostense y Beira y de don Juan Antonio Azcona y Escajadillo y, finalmente, que Mariano Barrera también concurría alguna vez y el declarante le reconvenía que José Gabriel Tupac Amaru no le contestaba ni le pagaba lo que le debía, encargándole le escribiese sobre el asunto. Inquirido sobre sus lecturas dijo que era aficionado a leer libros místicos y algunos de historia y entre estos los Comentarios de los Ingas por Garcilaso y que con sus vecinos don Manuel de la Torre y don Fernando Vila, habló algunas veces sobre el 
contenido de los Comentarios, de los que prestó un tomo a don Manuel, "y que lo más notable que hace memoria hablaron fue del gobierno de los indios en su gentilidad y de la admiración que les causó ver a los españoles a caballo y que al mismo tiempo también hablaban algunas cosas de España y esto responde" /16/. No fue esquivo a la pregunta más delicada: si había hablado de los privilegios de los caciques. Dijo que con Torre y don Juan Martínez de Rosas, europeos, habló de esos privilegios "y de que no se les guardaban por su pobreza e ignorancia" que fue lo que él dijo y sus contertulios le replicaron que "el ser pobres no les quitaba el ser caballeros". /17/ Todavía el oidor Arredondo le pidió que se explaye en su pensamiento y Montiel dijo: "que por no saber leer ni escribir muchos de los caciques y mandar en sus provincias los corregidores, sin que haya quien les contradiga, suelen atropellar a muchos, no solo indios sino a los demás; y que entre los privilegios que cree han dejado de guardárseles es el de nobleza, pues ha oído decir que algún cacique se le ha puesto en los obrajes". Hubo espacio para un poco de humor en el interrogatorio pues el oidor le preguntó si en sus conversaciones se mencionó a Tupac Amaru: Montiel dijo que por "bufonada" cuando Becerra pasó alguna vez por su tienda le llamaban Tupac Amaru y con Vila lo "chuleaban", diciéndole que don Vicente García le había de despachar a Valdivia. /17v/ En este punto, no era tonto Montiel, recordó también el paso por allí de Francisco Olea que apareció con Azcona. Los paisanos de Olea lo "sumvaban al verle hacerse caballero". No desdijo haber tenido intercambios de opiniones con Olea, pero dice que fue a raíz de que este dijera que los hijosdalgos de España eran más nobles que los indios caciques, pero "sin que con este motivo se profiriese por el declarante expresión alguna /18/ ofensiva a la fidelidad y obediencia que se debe al rey de España". Pero ya Arredondo se puso más agresivo y le manifestó la acusación de que al calor de una de esas conversaciones, había dicho que se vería a Tupac Amaru en silla de manos y otras de las cosas de que lo había tachado Olea. /v/ Todo lo negó y dijo que él y todos sus ascendientes siempre se han vanagloriado de vivir bajo la sujeción del rey que les ha concedido diversos privilegios. El interrogador le requirió los nombres de quienes habían estado presentes cuando lo visitó Olea y Montiel volvió a mostrarse irónico /19/ pues, estando allí Vila, Martínez de Rosas y Azcona: "luego que veían a dicho Olea comenzaban a zumbarle por haberle conocido que hacía de caballero, por lo que se pasaba un rato de risa, y que uno de los días que asistió a su tienda el citado Olea tuvo una disputa con un clérigo, don Vicente Centeno, que ya falleció, quien le dijo a Olea que los indios limpios eran tan nobles como los españoles sin que pasase adelante la disputa ni haberse metido en ella el que declara". / v/ Tres o cuatro días antes que lo arrestaran, Olea volvió por allí quejándose de que no había logrado conveniencia en esta tierra, a lo que el declarante le respondió: "echase la culpa a su poca suerte pues la tierra no era ingrata para quien se aplicaba, ni podía decirse extranjero pues estaban en los dominios de un mismo rey, y que alguna vez le pagó el declarante la cena en la fonda, y le prestó algunos reales, compadecido de su escasez".

Esta declaración tiene una clara intención de patentizar la condición del denunciante Olea. Lo presenta como alguien sin posición, que alardeaba de caballero. Lo deja además en situación económica precaria, no había logrado "conveniencia” y Montiel le enrostraba que no era por las posibilidades de la tierra, con lo que la culpa era del propio aspirante. Además, 
expresa Montiel una idea de pertenencia nacional pues le achaca que no era extranjero en Perú pues todos eran parte de un mismo reino.

/32/ Se insertó en los autos, de manera extemporánea como adelantamos, la declaración de Juan Martínez de Rosas, el 20 de enero de 1781. Este era oficial de la tesorería de la Real casa de moneda. Al parecer, este testimonio, de alguien que había aparecido en las conversaciones materia de escrutinio, se añadió porque fue contraria a la versión de Montiel, que de diversas maneras fue corroborada por los contertulios. Dijo que participó en conversaciones sobre la conquista y que allí Montiel "expresó que algunos conquistadores habían sido tiranos usando menos humanidad que el conquistador de México, manifestando bastante inclinación a los de su nación y queriendo persuadir que era de los de primera nobleza y distinción entre / $\mathrm{v} /$ los indios". Pero a la vez, sumándose a las apreciaciones de sus otros compañeros de conversación, favorables al intento de librarse de sospechas por parte del comerciante indio, dijo que Montiel le pidió ayuda para cobrar más de ocho mil pesos de Tupac Amaru, al que calificó de "gran perro".

/20/ El 23 de diciembre declaró Manuel de la Torre. Confirmó los intercambios de ideas sobre la conquista con Montiel y que le prestó un tomo de Garcilaso, pero dijo que nada hacía presumir una expresión opuesta a la subordinación. /21/ Sin embargo, "sabiendo el que declara que Montiel hacía de indio noble y apasionado a los ingleses solía tentarle por oírle, y nunca percibió otra cosa más de que defendía la nobleza de su nación y el manejo de los ingleses lo que siempre atribuyó a haber vivido en Londres”. Además, certificó que no habló de Tupac Amaru salvo cuando se comentó el alzamiento y mostró displicencia y enfado por haber perdido la dependencia de géneros que tenía con él.

/22v/ El 28 de diciembre llamaron a testificar a Fernando Vila. Confirmó que "zumbaban" a Olea porque presumía tenía mayorazgos en su tierra y le decían que no era tan caballero Montiel a quien llamaba cacique. Todo era un mero pasatiempo. Montiel llevaba enfado con Tupac Amaru e incluso dijo que, si el corregidor lo hubiera apresado por lo que le debía, no le hubiera pasado lo que le pasó. Según este testimonio, Montiel era más afecto a los peninsulares que a los naturales porque aquellos le habían dado de comer.

Siguen declaraciones de los asistentes, Melchor de Ibarra, José Bustinza y Juan Antonio Azcona, que no cambian nada de lo anterior. Montiel habría llamado a Tupac Amaru de "pícaro y ladronazo" y andaba melancólico por la pérdida de su dependencia. Las charlas eran de pasatiempo, nada se habló de la conquista, era cierta la arrogancia patética de Olea, Azcona dice que zumbaba a Montiel diciéndole "cacique noble". Todos los participantes en las tertulias depusieron en los autos. Todos procuraron desvincular a Montiel de posibles declaraciones sospechosas de infidelidad y, sobre todo, del rebelde a quien más bien tenía rencor por la deuda no pagada. Tanto los europeos como Montiel, se burlaban de la ostentosa pretensión de Olea de ser un caballero. Pero también lo hacían con Montiel por su orgullo de nobleza india. 
/33/ Quien salió a la defensa de Montiel fue el procurador general de los naturales don Alberto Chosop. Llama a Montiel "indio" preso ya por tres meses más o menos, sin que se le haya probado nada y más bien estar documentada la enemistad por la deuda, pide libertad bajo fianza o que se le siga la causa y pueda defenderse en forma. Fecha de 8 de febrero de 1781. Presenta el reclamo que hizo Montiel y decreto favorable de 8 de abril de 1780 para que Tupac Amaru le pague los más de $8,000(8,262)$ pesos que le prestó y que afirma no eran suyos sino de un tercero que sabedor de la demora de más de dos años en el pago y la voluntad de defraudar del deudor, iba a proceder contra Montiel. Se instruye al corregidor de Tinta para que ampare a Montiel y preste ayuda a su apoderado para que Tupac Amaru pague.

/41v/ En el documento aportado por Chosop, Montiel se presenta como ayudante mayor de la compañía de indios nobles del Cuzco y residente en Lima y dice, que habiendo ocurrido al Superior Gobierno para que el corregidor o cualquier justicia ejecute a Tupac Amaru por la deuda que se escrituró el 3 de enero de 1778 ante Andrés de Sandoval con plazo de tres meses y vencida por más de dos y medio años, se dio decreto favorable -que antecede- pero habiendo ido el apoderado Ignacio Aponte donde el corregidor Antonio Arriaga, quien dio auto de pago con plazo de tres días, pero no se le hizo saber porque el capitán Francisco Cisneros comisionado, no lo comunicó. Pide bajo protestas que se haga cumplir y denuncia el dolo de su deudor, fecha en Lima 6 de octubre de 1780. Nuevo decreto para que se cobre.

/52v/ Entonces se apersonó el protector de naturales en la causa. En el pedimento, José Baquíjano que era el protector, se refiere al reo como don Miguel Montiel y Surco, "indio noble" y comerciante en la capital que concurrió donde él expresándole estar preso por cerca de tres meses en mérito a una denuncia infundada de un capital enemigo suyo nombrado don Francisco Olea, relativa a cierta conversación que figuró le había oído apoyando los proyectos del rebelde Tupac Amaru. El defensor sostuvo que no se había probado nada y su defendido estaba perdiendo su caudal y siendo perjudicado, mientras las leyes previenen favorecer en estos casos a los indios. Que si no hay mérito se siga la causa y se le tome confesión o si no se le suelte. Lima 3 de marzo de 1781 el doctor Baquíjano.

Arredondo pasó al virrey sus "averiguaciones" para que con las noticias que llegaran del Cuzco se viera qué hacer con los reos que clamaban por su liberación, Lima 16 de marzo de 1781. Los presos se ponen en libertad por orden del virrey con cargo de que Arredondo los observe.

/57/ Entonces las cosas volvieron a ponerse complicadas para los sospechosos Barrera y Montiel. Varios datos de las declaraciones del proceso que se sacaron por orden del juez Benito de la Mata Linares, se mandaron reservados a Lima. Manuel Espinavat López, escribano habilitado por el visitador superintendente general de Real Hacienda (Areche) para practicar las diligencias en los autos que se siguen contra Tupac Amaru, certifica que de la declaración de Francisco Cisneros consta haber escuchado al rebelde que haría siete años tenía pensada la rebelión que sólo comunico con Mariano de tal, su apoderado en Lima. Y siguen en los autos las otras cartas de Tupac Amaru que involucran a Barrera y Montiel que son muy famosas, donde trata a Montiel como carísimo primo /59/. 
Areche escribió al virrey el 3 de mayo de 1781 diciendo se debía apresar a los mencionados que resultaban involucrados y /62v/ se busquen los autos del entroncamiento para que cuando él llegue, los vea y no quede una memoria de lo que "acaso es causa principal de este alboroto o rebelión de todos los indios del reino". El 21 de mayo Arredondo detuvo nuevamente a Montiel y Barrera y se les tomó confesión.

/64v/ Confesión de Montiel, con asistencia del procurador Chosop. Confirma sus datos básicos, aunque dice aquí que tiene 43 años y está soltero. El juez es más agresivo ya por las pruebas que tiene y hace uso de algunos pasajes de las averiguaciones anteriores enrostrándole que sí era confidente de Tupac Amaru, pero desde luego todo lo negó. Niega haber recibido carta (que no la recibió pues estaba en los autos cuzqueños) y que, si la había, debía ser en venganza por las diligencias que practicaba para cobrarse su deuda.

/71v/ Confesión de Mariano Barrera. Era cuzqueño, de oficio escribiente, soltero y de 30 años. Se reafirma en sus declaraciones previas y dice que fue apoderado de Tupac Amaru y añade que por orden suya también corrió unas diligencias concernientes a la electoría que pretendía en Cuzco Ambrosio Chillitupa, cacique de Oropesa, que por no haber recibido auxilios no siguió y cuyos autos posee. Luego niega que compartiera con Tupac Amaru sus ideas. En estos autos, Barrera se dice siempre español, por eso, a diferencia de Montiel, no tuvo la asistencia del procurador Chosop ni del protector Baquíjano. Lo representó un procurador que le fue designado y era Toribio Ramírez de Arellano.

En ese estado es que llegó la certificación de la implicación de Barrera en la confesión que dio en capilla el rebelde cuzqueño. /10o/ Hasta el 18 de junio de 1781 siguió confesando Barrera por esto, negando siempre que fuera cierto.

El fiscal acusó formalmente a ambos. Incluso, el acusador original, Olea, fue también apresado por no haber dado cuenta a tiempo de lo que sabía. Siguieron diligencias y un largo alegato de Baquíjano mostrando lo deleznable de las pruebas contra Montiel, las contradicciones de Olea, los testimonios que mostrarían más bien lo contrario, cómo buscó hacerse cobranza de la deuda, que si Arriaga lo hubiera detenido se habría salvado. El 30 de octubre, está la causa en su proceso. Como sabemos, ambos, Montiel y Barrera se acogieron al indulto que se promulgó luego de ejecutado Tupac Amaru. El 15 de septiembre de 1781, estando en prueba la causa, el protector de los naturales, el señor Baquíjano, pidió acogerse al indulto general a una lista de presos indios que estaban siendo procesados por su vínculo con la rebelión de Tupac Amaru y con "otras anteriores". Lo pide en virtud de que los propios Diego y Mariano Tupac Amaru, Andrés Noguera y Ninacatari, que siendo tan culpados habían obtenido el perdón.

\section{Segundo proceso y condena a Mariano Isidro de la Barrera (1783)}

El 2 de septiembre de 1783 el oidor Melchor Jacot Ortiz Rojano dirigió al virrey Agustín de Jáuregui los autos que le mandó pedir, obrados contra Mariano Barrera y consortes. Junto al 
proceso de Barrera, el virrey pidió al secretario de cámara Clemente Castellanos, que era actuario de la causa contra Felipe Velasco Tupa Inga por el levantamiento que pretendieron hacer en Huarochirí, una certificación de lo que allí apareciera contra Barrera. Castellanos certificó que sólo se encontró que, en el cuaderno tercero de los autos, en una declaración recibida a Andrés Mendigure por Manuel de Arredondo, dijo: "que en una ocasión que fue a casa de Mariano Barrera que vive en la Barranca y fue apoderado de José Gabriel, informándole que Felipe Tupa Inga le había visitado, le respondió: ese es Felipe Velasco no Tupa Inga quien conmovió diversos pueblos al principio de la sublevación de José Gabriel para ir al Cuzco en su defensa". Igualmente, en ese cuaderno tercero, en la diligencia de tortura que se le dio al reo Felipe Velasco, en su declaración figuran estas palabras: "que también hace memoria que el confesante le dijo a Carlos de Ochoa que para qué andaba Andrés Mendigure en festejos con Mariano Barrera siendo este un perdulario y que si su excelencia lo sabía no haría juicio de él”.

Castellanos, actuario también en la causa que sustanciaba Arredondo contra Andrés Mendigure, Mariano Tupac Amaru y otros reos por el "nuevo movimiento de las provincias", certificó que reconocidos los autos formados contra Andrés y Mariano, se encontró en el cuaderno sexto que se rotula "cuaderno de los autos que se siguen contra Mariano Tupac Amaru, Andrés Mendigure y otros reos sobre nuevos movimientos acaecidos en la provincia de Quispicanchi y otras incidencias, en la confesión que se le tomó a Mariano Tupac Amaru, resultó que lo visitaban sin frecuencia Mariano Barreda, Francisco Chillitupa cadete del regimiento de infantería, un cabo dragón nombrado Victorino, un cristalero cuyo nombre ignora que le parece vive en la Inquisición y que el cacique Caia Condori dará razón; y los domingos que iba donde SE, iba donde Barreda y donde Chillitupa, quedándose a comer algunas veces con Barreda. Preguntado si con alguno conversó sobre su estado o el de los indios o de su tío Diego Tupac Amaru o si Barreda le prestó algunos reales, lo negó y sólo habló con él para pedirle los títulos que tenía de su padre para presentarse a SE y que Barreda le entregó un borrador que está en autos. Preguntado por si habló acerca de que Diego bajaría a Lima y de que los indios no estaban enteramente quietos, dijo que una vez en casa de Barrera y presente Lucas Garay hablaron de ello y expresó que no bajaría por estar enfermo y recelar si algo le harían”. En la confesión de Mendigure también dice que se visitaban con Barreda y Chillitupa y que se quedaba a comer donde Barreda. Que habló con él y con el abogado Chavarría que les aconsejó en este punto que no bajase su tío Diego, que mejor estaba allá cuidando los bienes y familia.

Reunidos esos informes, también se sumó lo que resultaba contra Barrera en la causa que se siguió contra Manuel Perfecto Llacsa, cacique de Cayna en Tarma. De la carta escrita a don José Gutiérrez de la Parra por varios individuos del cerro de Yauricocha, aparece que, de orden de un Cosme Tupac Inga, se estaban repartiendo cartas para una conmoción general, lo mismo resulta de otras cartas copiadas donde también se expresa que el tal Cosme estaba unido con Manuel Llacsa y apeado en casa de este. Finalmente, en la confesión de Llacsa se lee que tuvo hospedado a Antonio Cordero a quien encontró en el Obrajillo, provincia de Canta, que iba enfermo y antes lo conoció en Lima cuando estuvieron presos. En las 
declaraciones de Juan de Gavidia aparece haberle dicho Barrera llamarse Antonio Cordero, el mismo que las citas anteriores identifican con el nombre de Cosme Tupac Inga. Todo se confirmó de otras confesiones y la del propio Barrera.

De tal forma que Mariano Isidro Cordero Barrera, libre por indulto, estuvo involucrado en más de una causa de infidencia, que se sucedieron a la rebelión de José Gabriel y mantuvo estrecho contacto con los Tupac Amaru que estaban en Lima luego del indulto y al poco fueron nuevamente procesados por los supuestos "nuevos levantamientos" que se estarían maquinando. El rebelde de Huarochirí, Felipe Velasco, no veía sin embargo con buenos ojos a Barrera, a quien acusaba de distraer en saraos a los jóvenes Tupac Amaru ${ }^{10}$.

En su confesión, Barrera, llamado también Cordero, declaró tener 28 años, de casta español, su patria Cuzco, estado soltero y oficio plumario. Allí dijo que también se apellidaba Cordero. Su salida de Lima se debió a unas tercianas que lo aquejaban. Quiso ir a Jauja, pero no pudo por no haber arrieros. Se presentó uno de Tarma con el que se contrató, pero lo llevó sólo hasta Obrajillo donde lo desamparó. En ese estado se encontró con Llacsa a quien conoció en los corredores de la Audiencia donde le dejó sus poderes para que le viera los pleitos que tenía pendientes. Lo llevó a su hacienda a principios de mayo, llevaba enfermo desde marzo. Le preguntan por su conocimiento de otro cacique acusado de intento de rebelión, llamado Pedro Nolasco Antonio Simbrón Apolibia (Apoquispilivia) y Pacheco, cacique y gobernador del partido de Checras, provincia de Chancay, acusado de incitación a la rebelión y dice que fue en la cárcel pero que no lo había visto después. Sigue su larga declaración, donde se le carea con Andrés y Mariano respecto de haber escrito a Diego Cristóbal. Los dos Tupac Amaru visitaban a Barrera en su casa, donde se hicieron festejos con música por varios días. Cuando habló Mendigure, confirmó que Felipe Velasco recelaba de Barrera y les aconsejó que no se acercaran a él. El fiscal evaluando sus declaraciones y los documentos, lo encuentra culpable de todo a fines del año 1783. Fueron condenados a destierro tanto Barrera como Llacsa y Simbrón.

\section{El destierro, el amor y la añoranza de la patria}

Comprobada su conducta sediciosa, posterior al indulto del que se benefició, Mariano Barrera corrió la suerte de otros muchos parientes de José Gabriel Tupac Amaru y personas que fueron encontradas culpables de intentos de alzamientos. Fueron desterrados del Perú y embarcados en dos navíos que sufrieron travesías accidentadas. Barrera fue enviado bajo partida de registro en el navío El Peruano como uno de 38 presos hechos por las alteraciones, alborotos y sublevaciones del Perú. Salió El Peruano del Callao el 13 abril de 1784 y no llegó a Cádiz sino a inicios de 1785 luego de diez meses de penosa navegación. En el largo viaje, 16 de los prisioneros encontraron la muerte, entre ellos Mariano Tupac Amaru. Barrera fue recluido en el castillo de San Sebastián junto con Juan Bautista Monjaraz Tupac Amaru, el

${ }_{10}$ Toda la información obra en el Testimonio de la segunda causa promovida contra Mariano Isidro de la Barreda por confidente del rebelde José Gabriel Condorcanqui conocido por Tupac Amaru, año de 1783. Real Sala del Crimen, escribano de cámara don Clemente Castellanos. AGI, Lima 1049. 
medio hermano del rebelde de Tinta y con dos reos de infidencia con los que había estado en contacto en Lima, en la prisión que sufrieron al inicio de la sublevación y en las distintas juntas que patrocinaron los intentos de alzamiento en Huarochirí y en Checras. Uno de ellos, Felipe González Rimay Cochachín, estuvo también involucrado en un alzamiento en Huaraz y luego fue cómplice de Felipe Velasco Tupac Inca. El otro, Pedro Nolasco Simbrón, era un altivo curaca que intentó rebelarse más de una vez en las serranías de Lima y al que Barrera apoyó y siempre respetón ${ }^{11}$. Tres años pasaron en esa prisión hasta que el rey decidió dispersar a todos los sobrevivientes presos de las alteraciones peruanas. La trayectoria de Barrera tuvo dos etapas más antes de llegar a su destino final como desterrado en Orán, en la línea de guerra contra los musulmanes en Africa. Luego de San Sebastián de Cádiz fue conducido a la cárcel de Málaga y todavía fue detenido en el cuartelillo de Cartagena para ser embarcado a su duro destino final ${ }^{12}$.

Nunca dejó de reclamar contra su estricto destierro. En un memorial de 20 de marzo de 1784, Barrera, preso en el cuartel de prevención de infantería en Lima, diciendo que estaba en esa condición por haber sido complicado en la rebelión intentada por Felipe Tupa Yupanqui, pedía una copia de su causa que era de derecho, pero ni su abogado ni el procurador quisieron interceder, por lo que escribía pidiendo ese derecho antes de embarcarse a su destierro. Ya sabía que debería enfrentar una difícil situación y debía hacerlo de la mejor manera posible, conocía los entretelones del manejo de la justicia. En su cautiverio inicial, mostró su vena literaria, no por nada había sido "plumario" y representado en los estrados a José Gabriel. En 1787 escribió un largo manifiesto que permanece inédito. Lo hizo para pedir clemencia y para volcar su experiencia y conocimiento del mundo andino, como una forma de proponer medios para extirpar las causas de las alteraciones pasadas. En Orán pidió que le diesen ocho o diez reales diarios como había recibido en Cádiz. Mostró una carta de Juan Monjaraz, que era Juan Bautista Tupac Amaru, que había llegado a Ceuta por ser hermano de José Gabriel y Diego Cristóbal, donde constaba que allí recibía seis reales. Le respondieron al gobernador de Orán que no correspondía, que Monjaraz estaba sólo por ser pariente y libre en Ceuta y que a Barrera Cordero se le condenó a ración y sin sueldo.

Ya en Madrid, a donde llegó en 1792, hizo una instancia reclamando que en el cumplimiento de su sentencia debía tenerse en cuenta los cuatro años que sirvió bajo el comando del coronel Miguel Torrejón en Orán. Aportó una certificación de Francisco Antonio Calderón firmada en la Línea de Orán el 29 de diciembre de 1791, sobre su buena conducta allí, desde 1788 hasta 1791. Había sido nombrado cabo en los Reales trabajos, supliendo a un cabo de brigada y por su buen proceder se le destinó a la provisión de víveres de la tropa, de guarda almacén de harina. En otra instancia de 1793, Barrera se presentaba como subteniente de las milicias

\footnotetext{
${ }^{11}$ AGI, Charcas 598. Hay sin embargo una información contradictoria que señala que Cordero Barrera fue recluido en el castillo de Santa Catalina.

${ }_{12}$ AGI, Cuzco 29, expedientillo de Mariano Isidro o Isidoro Cordero y Barrera o Barreda. Años 1785 a 1792 y 1793. Causa por ser complicado en los alborotos del Perú, de que resultó condenado al presidio de Orán por ocho años. Su libertad por haber cumplido y oficios de hacienda para su colocación. Una presentación general sobre el destino de los desterrados por las sublevaciones del Perú en Alfredo Moreno Cebrián y Jorge Chauca García, "Los ecos indianos del gran levantamiento de Tupac Amaru y su proyección peninsular: un episodio olvidado". Revista de Indias 279 (2020), 317-344.
} 
urbanas del regimiento de la ciudad del Cuzco, ya no dijo nada de ser escribiente. Reivindicaba su indianidad cuando dice que en su condena tampoco se tuvo en cuenta "el goce de los privilegios, prerrogativas y exenciones generales concedidas a su nación"13. Es muy reveladora la distinta estrategia de nuestro personaje cuando estuvo ante los tribunales peruanos, identificándose como de casta "español", como vimos en su momento, y luego ante los españoles, reivindicando su nación indiana y los privilegios Reales que reclamaban los nobles indios, de los que hablaron tanto en las tertulias descubiertas cuando lo apresaron entre los sospechosos de tener vínculos con el estallido de la revolución.

El término de su prisión de ocho años se contaba desde marzo de 1784 cuando fue condenado. Ya estaba a punto de cumplirse. A pesar de su buen proceder, en 1791 le impidieron regresar a la península y le previnieron que no lo intente. Llegó a Madrid en virtud de orden de 19 de enero de 1792, lleno de males por los malos tratos y sordo por las ruinas (terremoto) de Orán y de los fuegos de la artillería de los moros en el último sitio de la plaza.

Segú reza un diario escrito por el mercedario Tomás Catalá desde la plaza de Orán: "El día 9 de octubre de 1790, a la una y minutos de la mañana fue el terremoto. El comandante general, su hija y criados perecieron entre las ruinas del palacio de la Alcazaba. El gobernador en las ruinas de su casa. Tomó el mando en jefe el brigadier coronel de Navarra, conde de Cumbre Hermosa, cuya hija pereció también. Al amanecer ya se contaban 18 terremotos. Solo de tropa y empleados fallecieron 639 personas y del pueblo etc. hasta 3.00o. De tropa solo quedaron 1.600"14. A la tragedia del sismo se sumaba el acoso feroz al que sometían a la posición española las tropas del bey de Mascara. En medio de la furia terráquea, la posesión española en el norte de Africa vino también a derrumbarse cuando luego de largas negociaciones, dejó la plaza en febrero de 1792. Poco antes el maltrecho indio peruano había logrado salir de vuelta a la península.https://www.elche.es/wp-admin/post-new.php?lang=es - ftn1

Entonces pidió nuevamente por su buen comportamiento, por "los privilegios y gracias especiales concedidas por los reyes de España a los indios" y por no poder conseguir cómo ganarse la vida, que le dieran una asignación "como se ha hecho con los demás que vinieron del Perú de resultas de la sublevación general de aquel reino". También consideraron sin asidero su nuevo pedido debido al origen de su prisión, condenado a destierro perpetuo y prisión de ocho años a diferencia de otros. Pero por su buen comportamiento, lo penoso de su historia, el soportar un terremoto y una cruenta guerra y además ser "bastante despejado y racional a lo cual agrega que sabe escribir más que medianamente", se sugiere que le den un empleo subalterno correspondiente a su aptitud, con fecha 17 de agosto de 1792 . No consiguió nada, sin embargo, por la competencia y falta de apoyo, por lo que reclamó que se le diera un empleo sin pasar por la superintendencia de hacienda ni la dirección de rentas y que le diesen algo para sobrevivir. Lo cual al fin se le concedió.

Once meses de penuria pasó en Madrid sin lograr colocarse y, en marzo de 1793, expuso que se había casado con María de Luque quien había conseguido permiso para restituirse a su

13 Todos los documentos en AGI, Cuzco 29.

${ }^{14}$ Archivo Histórico Municipal de Elche, Sig. B.6o.

Revista Revoluciones $\mathbf{- 1 8}$ - Vol. 3, Nº 5 (2021), pp. 5-19 Esta obra está bajo una licencia internacional Creative Commons Atribución 4.0. 
domicilio y que las alteraciones de su país se encontraban enteramente extinguidas. Pidió que, para poder estar con su mujer, le permitieran volver al Perú y que la orden de su colocación en España sea entendida para el virrey de Lima donde se le ubique. La mujer que se casó con Barrera se llamaba María de Luque. Compartía penurias con Paula de Castro, una mujer mayor que era tía de Diego Cristóbal y su tía abuela ${ }^{15}$. Fueron desterradas y conducidas a España en el San Pedro de Alcántara, luego de un viaje todavía más largo y lleno de accidentes que el del buque El Peruano, recién el año de 1786. Depositadas en el hospicio de Cádiz, también salieron de allí cuando los presos se dispersaron para ser enviadas a Madrid donde se alojaron en el colegio de Monterrey. Ellas se presentaban como indias nobles y decían haber sido detenidas sólo por su parentesco con los líderes. María de Luque tenía 30 años en 1791, era natural de Surimana, sobrina de Diego Cristóbal como hija de una prima suya y estaba comprometida en matrimonio con Mariano Cordero o Barreda. No podemos determinar si el compromiso fue anterior al destierro o si se fraguó en el tiempo del cautiverio gaditano o sólo en el momento que ambos se encontraron en Madrid cuando Mariano llegó abatido por los sucesos de Orán.

Fruto del naufragio de la nave que la condujo a su destierro, del que salvó la vida cogida a un madero, María estaba gravemente enferma, a punto de perder la vista, sumida en una profunda tristeza. Escribió el 20 de septiembre de 1791: "tampoco puede negarse a los gritos de la naturaleza con la continua memoria de sus hermanos, patria y parientes, hallándose por esto, cercada de una profunda tristeza, a más del abandono de su casa y hacienda que todo fue interceptado por aquellos jueces". Ella y su tía repitieron lastimeras instancias pidiendo una mínima vida digna. Lograron salir del colegio de Monterrey y alojarse en vivienda particular. Tuvieron un modesto estipendio y sin ocultar la melancolía de la distancia de su patria, los muchos sufrimientos que ya habían padecido por causa tan poco plausible de merecerlos y que las turbulencias del país ya estaban apagadas, pidieron regresar a sus hogares. Cuando los pedidos parecían llegar a un buen resultado, María contrajo nupcias con Mariano. La afirmación de Mariano no era exacta pues recién consta el matrimonio realizado el 4 de abril de $1793^{16}$. En el acta de matrimonio figuraba como hija de Ignacio y María Castro, pero en las listas de presos hechos después del alzamiento, figura como hija de Asencia Castro que era prima de Diego Cristóbal. Una de esas listas señala que estaba entre los presos Asencia Fuentes, prima de Diego Cristóbal y María Luque, "hija de la dicha Ascencia Castro"17.

Con todo lo alegado por el elocuente Barrera, incluido el matrimonio con María Luque, que ya estaba pactado, por fin, el 23 de marzo de 1793 se le concedió el permiso de regresar, advirtiéndole que observara la conducta que había llevado hasta entonces. Pero no fue fácil. Hubo todavía un conflicto de informes mientras pedía pasar de Coruña a Buenos Aires y se advertía que no había manera de regular el viaje por tierra desde allí a Lima. No fuera eso suficiente, la mujer enfermó malamente y se detuvo el expediente mientras se esperaba el

15 AGI, Charcas 598.

${ }^{16}$ Matías Fernández García, Parroquias madrileñas de San Martín y San Pedro el Real, Algunos personajes de su archivo. Madrid, 2004, Caparrós Editores, p. 173.

${ }_{17}$ AGI, Lima 1045. 
resultado de su mal estado. Una vez sana, todavía se pidió que se informase al ministerio de hacienda de Indias sobre todo este caso y que se supiera allí que la autorización se debía al matrimonio y a su buen comportamiento y que se le costease el pasaje por mar. Hasta aquí la historia con fecha de 17 de agosto de 1794. No tenemos constancia de que Mariano y María lograran el anhelado regreso a la patria. Sus huellas se pierden, como languideciendo en agonía, producto de prisiones, destierro y penurias con las que pagaron el atrevimiento de que unos pueblos oprimidos hayan querido rebelarse contra la tiranía. 